\title{
The Role of E-government in Reduction of Information Asymmetry in Developing Countries on the Example of Azerbaijan
}

\author{
Aida Guliyeva, Ulviyya Rzayeva* \\ Department of Information Technologies and Economy, the Faculty of Technology and Design, Azerbaijan State University of \\ Economics (UNEC), Baku, AZ1001, Azerbaijan
}

Copyright@2018 by authors, all rights reserved. Authors agree that this article remains permanently open access under the terms of the Creative Commons Attribution License 4.0 International License

\begin{abstract}
At present, the issues of expanding government intervention in the economy and advantages of state regulation are being discussed quite actively. At the same time, it is wrong to turn a blind eye to the problems caused by such interference. One of the "failures of the state" is connected with information asymmetry arising due to monopolization of information by employees of the state apparatus who use these advantages in their own interests. In any state system, there will always be the mechanisms of supporting the representatives' exclusivity in relation to the rest of the population. The formation of an electronic government with the use of modern information and communication technologies allows significantly increase information transparency in the state structures. The article considers asymmetry of information held up by the power and conformism of the society maintaining the idea of privacy. In addition, the paper suggests a multi-level approach (macro-, meso- and microlevels) for managing competitive advantages, which allows balancing of economic interests in terms of reducing information asymmetry.
\end{abstract}

Keywords Asymmetric Information, Information and Communication Technologies, E-government, Transaction Costs, Multilevel Measures

\section{Introduction}

The development of a country's information space is the determining factor and marker of the progress level of the society. Revolution in information technologies directly affects the political, economic, social and cultural spheres of public life, changes the shapes of people behavior, the attitude of citizens to authorities and their readiness work for the benefit of the state, and create values in the broadest sense of this word. However, today in Azerbaijan the content of information material comes down to the description of separate acts of corruption; there is no practically uniform information that reflects the sources of venal practices, its negative consequences and positive examples of counteraction. A monopoly on information that has become an attribute of power leads to the fact that the authorities are not able to make rational decisions, at least in view of the lack of complete information required for such actions. The power is forced to act under conditions of limited rationality, which means bias in the process of regulating certain social processes. In addition, there are not any Azerbaijani researches in the field of corruption and positive impact of anti-corruption activity on minimizing the asymmetry of information [1].

The article examines the impact of the electronic state (e-government) on the universal organizational values such as transparency and accountability, when transparency is provided by ensuring citizens' admittance to state information, accountability - by the conferment official status to the disclosed information. Here we also should emphasize the importance of state information systems' audit that provides access to information.

Paragraph 2.1 of the article considers globalization as the main factor of information risks and related information asymmetry, which adversely affects decision-making at the state level. In paragraph 2.2 the influence of information asymmetry, formed by transaction costs on the functioning of the institution of public services is analyzed in detail. Paragraph 2.3 reveals development, perspective and problems of e-government in Azerbaijan. Multilevel approach to the reduction of information asymmetry in governmental structures is proposed in paragraph 2.4. The conclusion of the article contains a brief statement of the obtained results; an attempt to forecast the development of the examined issues is made; essential directions for further researches in this field are determined. 


\section{Materials and Methods}

The article's object is the consideration of information asymmetry in the framework of developing country's administration in an electronic era. The purpose of the work is justifying the need of ensure the information openness, which is impossible in view of an absence of legally fixed requirements for procedures and means of information and communication support for disclosure of governmental information in Azerbaijan. The relevance is the necessity of studying information asymmetry phenomenon, scrutiny of the international experience in its decrease, and as a result, reduction of bureaucratization's influence on the relations between citizens, business subjects and the power. The subject of methodological research is the analysis of e-state institutions for improving the quality of public administration.

These steps will allow defining a package of governmental measures, providing growth of Azerbaijan economic competitiveness on the world scene.

\subsection{Globalization as the One of the Main Factors of Information Asymmetry}

In XX century, interest in problems of an irregular economic development was largely due to the problems of world economy's formation, which included the challenges of developing countries [2]. Thus, the number of autarkic "theories of backwardness" was created within the framework of neo-Keynesian direction, described in the works $[3,4,5,6]$ and etc. In these researches, the gap in levels of development was driven by low degree of self-reproducing equilibrium in developing countries. Neo-Keynesians suggested that removal of the system from this state of equilibrium would cause the transition to self-sustaining growth and finally reduce the gap in economic development levels. Hirschman [7] offered the concept of no equilibrium growth, based on the fact that misbalance in the economic system was the stimulus for investment, and thus, its maintenance would lead to economic growth in developing countries.

Supporters of neoliberalism advocate the principle of self-regulation that is free from an excessive legislation. Until recently, this stream was accepted as universal remedy for economic development, but today it does not consider conditions and specifics of developing countries. Under the pretext of "corrections" undertaken in developing countries' economy (according to standard "recipe": liberalization of the prices and finance, privatization, ensuring full openness of the markets and their orientation to export, guarantees of profit's export and etc.) the actual desouvereignization of these countries and imposition them the certain place in the global economy are carried out [8]. The leading idea of neoliberalism can be formulated as follow - the intensification and the world distribution of free market both extensively (by international scale), and intensively (affecting all spheres of society life). Thus, neoliberalism shows basic relationships with globalization, especially in the economic sphere.

Globalization began to be actively studied from 1990th, resulting in creation of completely new directions in modern economic science and new theories of international relations. In the context of this research, it would be desirable to highlight J.-M. Siroen's [9] manuscripts in terms of clarification of globalization's essence. The author investigated many asymmetric aspects of international economic relations based on this difficult phenomenon. Having contradictory and asymmetric character, globalization acts as a catalyst of conflicts and financial and economic crises [10]. Enlarging gap between poorest and richest countries forms and increases global asymmetries not only in economy this phenomenon is typical for many spheres of public life - educational, scientific and cultural.

Interesting views of how the principles of globalization in some way discriminate not only developing states are offered in Kacowicz's paper [11]. A large part of the population in OECD countries also suffers from the effects of an unbalanced globalization policy, facing the problems of economic inequality. However, contradictions and asymmetries of global economic development have one very important aspect: it is the source of continuous progress of world economic system. From such point of view significant functions of economic development's asymmetry are:

- distributive function (determination of public product's distribution parameters);

- differentiating function (differentiation of producers and consumers);

- integrative-disintegrative function (integration of the isolated systems into unified economic system and destruction of the old ones);

- $\quad$ stimulating-dissimulating function (simultaneous stimulation and limited economic growth).

With the development of the population's education and progress of technology, the maintenance of monopoly on information requires the allocation of separate resources. This process results, on the one hand, by development of propaganda institutions, and on the other, by the legal security of privacy. In these conditions, when the government applies more and more efforts for forming "unilateral mirrors", the real rulers are not those who are richer or smarter, but those who are on the right side of the mirror.

At present, a number of studies devoted to optimizing the system of public administration note the qualitative leap in essence and content of power communications [12, 13]. The axiological space of bureaucracy, mentality and styles of public management is changing during the process of state evolution. The initial asymmetry between society and the state is gradually leveled, bringing these two 
centers of social attraction to common goals, unified standards, interests and even the volumes of influence.

Analysis shows that in order to reduce the level of bureaucratization, the principles of horizontal cooperation, network structures, mutual agreements and treaties play an increasingly important role. Economic entities can achieve the greatest utility in the process of developing competitiveness and innovations [14]. Openness and availability of information are necessary in order to business, power and another structures reduce bureaucracy and, as consequence, corruption.

Today "symphony" of the state and society becomes an indispensable condition for the effective development of the economy, culture, science and technology. Thus, the form of interactive relations arises and develops due to the application of innovative approaches in public administration. The so-called "new public management" means that the traditional hierarchical, formalized and monopolistic activities of the state apparatus are penetrated by the methods, which are used in private corporate governance practices [15]:

- Traditional state planning mechanisms are replaced by adaptive;

- hierarchical state structure is transformed into the network (network state), which increases the flexibility and efficiency of managerial decision-making;

- $\quad$ feedback mechanisms with society (interactivity) are strengthened;

- the bureaucracy becomes client-oriented (service state);

- power communications are transferred into the electronic form (e-government).

However, first, such processes of conscious transformation of the state and society do not take place without problems: often theoretical developments relating optimization of power communications remain only at a conceptual level and do not get applications in real practice. Secondly, the processes of improving the mechanisms of public authority are largely tied to the national specifics of a particular country and they are not unified from the standpoint of the universal managerial technologies. Moreover, several decades ago, governments of the United States, Britain, Germany and a number of other Western European countries were the undisputed leader of administrative schools and state practices for the application of effective management. However today eastern countries such as South Korea, Singapore, and Japan have already reached the introduction of information technologies into the management system, attained the minimum level of corruption and irrational losses [16].

\subsection{E-government in the Framework of Transaction Costs and Contract Theory}

In the developed world, there was transition to the new concept of the state, which fixed the choice between liberal and social state in favor of developing an idea of effective state management within the theory and practice of the so-called e-government. The formation of the e-government system envisages the introduction of digital ICT in the work of the state apparatus that allows improving the quality and state services' effectiveness for society, reducing bureaucracy and the costs of maintenance of the state, significantly increasing the level of governmental services' accessibility for all citizens.

We are talking about the current formation of the global ICT paradigm for socio-economic development, and the most important part of this process is the reform of public administration based on the principles of creating the national e-government system.

Therefore, the theory and practice of e-government is relevant for Azerbaijan. Moreover, the implementation of administrative reforms in this direction is especially relevant for Azerbaijan, where transaction costs are very high, and this is unmediated indicator and result of inefficient state management.

It is known that Ronald Coase entered the concept of transaction expenses in his famous article "Nature of Firm" in 1937 [17]. The most common definition of transaction costs is given through the concept of the system functioning's costs in contrast to the production expenses. Transaction costs are the central explanatory category of all neoinstitutional analysis. The orthodox neoclassical theory viewed the market as a perfect mechanism, where it is not mandatory to take into account the costs of service. Coase showed that it is necessary conducting negotiations, carrying out supervision, establishing relationships, and eliminating disagreements between each deals. Initially, he determined the transaction costs as "the cost of using the market mechanism”. Later, this concept acquired a wider meaning: any kind of costs accompanying the interaction of economic agents regardless of where it takes place - on the market or within the organization - are not free of friction and losses because there is business co-operation in the framework of hierarchical structures (such as firms). Transaction costs include the costs of collecting and processing information for decision-making, monitoring compliance with contracts and enforcing their implementation.

The emergence of such kind of costs is usually caused by asymmetric information and attempts to overcome the possible opportunistic behavior of the counterparty: it is necessary to spend time and money for search of potential buyers or sellers. The incompleteness of the available information turns additional costs associating with the purchase of goods at prices above the equilibrium (or sales below the equilibrium) and with the losses arising from the purchase of substitute goods. These costs are not only in the private sector when doing the business and the preparation of the relevant contracts. They play an important role in the functioning of public services' institution.

The costs of opportunistic behavior are also related to 
the asymmetry of information, although they are not limited by it. The fact is that behavior after the conclusion of the contract is very difficult to predict. Dishonest individuals will minimally satisfy terms of the contract or even evade from their execution (if sanctions are not provided). Such moral risk (moral hazard) always exists. It is especially important in the conditions of joint works working in team when the contribution of everyone cannot be accurately separated from efforts of other members of team if potential opportunities of everyone are completely unknown.

When Coase developed his theory in the 1930s, hardly anyone could imagine that the development of ICT would make possible to embody still the nonexistent concept of the electronic government.

During receiving state service (in other words, carrying out transaction on its receiving), a citizen faces number of transaction costs, for example, costs of searching for information about the list of documents, or the costs associated with violations of the procedure for providing information from government officials.

Meanwhile, one of the goals of creating e-government is reduction of transaction costs and increases the speed of transactions, achieved by ICT. Thus, the use of e-government technologies is guided by the Coase's theory: the more persons (or institutions) use an electronic way of interaction; the transactions between them are quicker and more effectively carried out.

E-government technologies are seen to be effective not only in the provision of public services to the population, but also in intra-state interactions. To carry out its own functions, the state needs both material resources and labor. The acquisition of these resources is mostly done by the state based on contracts.

For the state as a principal, the conclusion of the contract about hiring an official is always connected with the incompleteness of information, in connection with which there is the problem of agent's moral risk. E-government technologies, among other things, reduce the monitoring costs caused by the post contract activity of the agent [18].

Moral risk is a kind of post contract opportunistic behavior when the activity of the agent is unobservable for the principal, which allows the agent to make less effort in the framework of his activity, in other words, to shirk off duty.

The concept of contract incompleteness is easily explained through the idea of a full, absolute contract in which all options for agent behavior under any conditions is prescribed. Absolute contract is almost impossible because of the information asymmetry and the limited rationality between an agent and a principal. Incomplete contracts allow the agent working not for the result (for the benefit of the principal) but for the fixed indicator. In the conditions of the incomplete contract, the agent seeks to minimize his own costs for contract's implementation, i.e. to carry out what is formally prescribed, and do not carry out what is not prescribed, but, possibly, is meant by the principal. Thus the agent, probably, will not carry out those conditions, which are registered in the contract. Other examples of unfair behavior can be conscious delay of performing procedures, registration of certain documents retroactively, provision of incomplete information to the citizen, etc. All these factors greatly reduce the efficiency of the public sector [19].

The introduction of the idea of positive transaction costs into the economic science was major theoretical achievement. They are not directly related to the value creation processes, but expenses accompany the transfer of property rights to this value [20].

\subsection{E-government in Azerbaijan}

The main strategic direction for the further development of Azerbaijan is achievement of sustainable economic growth and progress through the elaboration of the non-oil sector and diversification of the economy [21].

To this end, the reduction of the natural resources and the provision of the non-oil factor's advantage in the composition of the GDP are envisaged, as well as the formation of the state budget, the creation and development of powerful motivational mechanisms for expanding the application of innovations in the economy. Ensuring social and economic development of all Azerbaijani regions at the level of modern requirements and increasing the competitiveness of the economy using available resources and geographical location will create conditions for national products occupying the worthy place in the world market.

To date, in Azerbaijan serious steps have been taken in this direction. First of all, state structures have been created, which are responsible for the ICT development, the formation and progress of information society, the multi-purpose sectorial program "Electron Azerbaijan", as well as a number of laws regulating the development of this field, including "Law On Telecommunications", "Law On Electronic Commerce", "Law On Electronic Document Management and Electronic Signature”, etc. Unfortunately, many norms do not function due to lack of appropriate infrastructure, low level of computer literacy, and absence of normative legal practice of relations in the Azerbaijani Internet sector.

In Azerbaijan, the construction of the e-government institution is one of the priority tasks within the framework of the e-Azerbaijan program, the implementation of which is facing the Ministry of Communications and High Technologies. However, often the initiatives of this institution are hampered by the reluctance of other entities to allow interference in their own affairs.

The main problem is the low level of legal literacy, people cannot understand why they need e-government, and do not trust electronic document management and technical devices. In order to eliminate this chasm in the 
minds of the population, many projects are being put into practice: TV programs, seminars, trainings. This process involves not only state structures, but also representatives of the private sector, whose interest in the development of computer literacy cannot be overemphasized. However, unfortunately, the country does not carry out fundamental scientific and sociological research in the field of information society development, forcing them to refer to the practice and experience of foreign countries. The level of development and application of ICT achievements by regions is too differentiated, and sometimes some steps taken in the field of legal regulation of ICT seem not logical. The results are the "dead" laws "On electronic commerce” and "On electronic document management and electronic signature”.

Another problem is the fact that various bodies, not coordinating their actions, not adhering to common standards, created completely inconsistent neither technically nor normatively internal information systems. Here we can say that different ministries are at different stages of the formation of the electronic government: some departments have only a page on the Internet, while others are already in the phase of interactions. Not so long ago, an automated tax declaration system and a customs infrastructure were presented; the prosecutor's offices establish departmental information kiosks. All these projects are welcome, but there is no clear unified picture of the situation, they will later have to be modified. In addition, projects are initially technically implemented, then normatively regulated, and not vice versa. Therefore, talking about concrete achievements in the field of building e-government today is deceiving of statistics.

The main problems in the formation of an information society are connected with the lack of specialists in the field of e-administration and the absence of coordination between government agencies. It should be noted that today the leadership of the country faces a dilemma concerning to the necessity of forming a scientific legal doctrine of ICT development. It is possible to follow the western way of liberalizing of use and development of information resources and communication technologies, or to choose the eastern variant of strict regulation.

\subsection{Multilevel Approach to the Reducing of Information Asymmetry in Governmental Structures}

Information asymmetry deepens due to the use of bureaucratic procedures by officials and rules that are inaccessible and are often unknown to business entities. As a result, every bureaucratic agency becomes a monopolist in the field of the permissive system in the organization of any activity, creating administrative barriers, overcoming of which causes an increase in the transaction costs in interactions between economic and power actors. Thus, to reduce the bureaucratization of business and government positions, it is necessary to reduce the information asymmetry existing in their relations. In this regard, the need to study the phenomenon of information asymmetry, the world experience with its reduction, and as a result, reduction the influence of bureaucratization on the relations between business and government subjects, is actualized. At present, the main efforts to reduce the costs of information asymmetry are focused on increasing the transparency of issuers and the market, and these efforts are made by only two groups of market participants: regulators and so-called professional participants - investment institutions, while issuers (with rare exceptions) show much less interest in disclosing information.

Increase in information openness of state activity and local authorities, availability of relevant information for citizens and organizations, as well as creation of mechanisms for public control of their activities are provided by creating:

- $\quad$ state information resources, as well as information resources containing data about activities of federal public authorities, with the access's provision to them by citizens and organizations, including via Internet;

- a unified navigation system via Internet throughout national information resources, as well as information resources of federal authorities;

- infrastructure of public access points to information about the activities of federal public authorities and state information resources;

- $\quad$ systems of registration and processing of citizens' requests for information and control over their execution;

- $\quad$ systems for publication and dissemination of information about the activities of federal public authorities.

This process will allow defining a set of public policy measures ensuring the competitiveness of the Azerbaijan economy on the world stage.

These goals are reflected in the "Development Concept Azerbaijan 2020: Looking to the Future" [22]. One of the main pillars of this development is ICT, as new economic sector with high growth rates, which plays the role of modern and multifunctional infrastructure, as well as the leading force of all-round socio-economic progress. By the decree of the state head, The Strategic Roadmap for the Development of Telecommunication and Information Technologies of the Azerbaijan Republic was published; it is one of 12 maps aimed to the development of the country's economy [23]. As a result of the work for the ICT development in Azerbaijan, important steps have been taken to accelerate the country's integration into the global electronic space, the emergence of new forms of social and economic activity (e-government, e-commerce, distance education, etc.), the creation of information and knowledge market, the growth of efficiency in various sectors of the economy, the improvement of the quality of products and services. 
At present e-document circulation is more widely used in the banking sector of the country, where market participants intend to adopt the practice of digital banking, interacting with payment systems, mobile e-wallets, e-commerce platforms and social networks [24].

Next, a multilevel (macro-, meso-, micro-) complex of measures aimed at reducing information asymmetry will be proposed. These measures imply priority actions at the state level (development of strategies, programs, mechanisms of de-bureaucratization of business and governmental relations), at the level of departments (ensuring transparency and accessibility of information in framework of an enterprise) and at the level of population (development of standards for the provision of public services and control mechanisms by civil society) were singled out.

\section{Macrolevel Approach}

At the macrolevel the communications and governmental relations are complicated, since there is a need to provide big amounts of data at different levels and different spheres of society. Within the framework of public relations, there is information that is subject to special legal regimes: state secrets, commercial secrets, official information, and tax and bank secrecy. The peculiarities of these regimes require the development of unified approaches to the legal regulation of information relations. The circulation of these types of data requires the observance of both public and private interests, which can be achieved only by establishing clear legal boundaries for its use and dissemination.

Among the basic applied issues, it is necessary to focus on interdepartmental information asymmetry. In most cases its essence is the absence of legal regulation of the information transfer between state and municipal authorities, which is expressed in the presence of a fragmentary, incomplete and, as a consequence, low-value information for making managerial decisions at the macrolevel. The information load becomes intense, first within the framework of state financial control, which means additional costs.

Therefore, the causes of information asymmetry at the macrolevel can be called by

- political and economic barriers (for example, sanctions);

- $\quad$ social and moral barriers that have arisen because of historical facts or sustainable perceptions of each country.

Analysis of information asymmetry's influence on the Azerbaijan economy allows proposing the following measures to reduce it at the macrolevel by the formation of a model of a subsidiary state that interacts with civil society and is characterized by the openness and accessibility of information about public services through the e-government system. This approach provides:

- formation of the electronic subsidiary government system, inventory of the state;

- $\quad$ consistency of laws;

- maximum information openness of all authorities and management.

At the macrolevel, e-government as a subject of state regulation reduces information asymmetry in the way of organization of public administration on the basis of electronic means of information processing, transmission and dissemination; interactions of public authorities and society using ICTs; the transformed ideas of electronic business for the government and state organizations; the automated public services which main functions are providing free access of citizens to all necessary state information (taxation, registration of vehicles and patents, issue of necessary information, conclusion of agreements and registration of materials and equipment supply and etc.).

\section{Mesolevel Approach}

In the era of constant changes and uncertainties, the effectiveness of economic actors depends on complete ideas about the surrounding phenomena and processes. Therefore, in the economic systems the main factor in achieving success is information that allows correct assessment of future actions and attained results, and serves as an important source of the company's competitive advantage, hence contributes to the acquisition and strengthening of market power. In this regard, information is valuable, that is, it acts as a commodity demanded by economic entities. At the mesolevel, information asymmetry is characterized by

- difficulties in defining and reaching the target audience (it is hard to convey information correctly and completely, taking into account differences in perceptions, traditions, education, religion, etc., for all consumers);

- different levels of access information, products or services (for example, information about tourism in the country can be distributed to people from other countries, but the number of tourists will not grow, as well as the frequency of visits to the country because of the high price of trips).

At the mesolevel asymmetric information can arise also in case of economic assessment of various markets, for example, of labor market. The American economist $\mathrm{K}$. Arrow [25] has investigated this issue in a general view. In this case, information asymmetry means a situation where labor market participants in the context of the relations between employers and employees do not have the same and reliable information. Despite the fact that such information as parameters of economic and financial activity, data on the number and composition of employees, their wages, working conditions and etc. can not constitute commercial secrets, employers, especially private enterprises do not always inform about them a potential 
employee. In turn, the employee is not inclined to give full information about himself.

Unfortunately, it can be noted that, unlike the developed countries, Azerbaijan still does not have an integral national concept regulating relations at labor market in the era of information economy and a principled position relatively the development of the electronic labor market and its state regulation. Accordingly, there are no sections and divisions in legislative acts that characterize the specific mechanism of the labor market functioning in an e-state. The basis for action in this area can be foreign experience, as well as the ILO's concept of decent work in the modern information society, which includes four strategic objectives: fundamental principles and rights at work, employment, social protection and social dialogue [26].

At the mesolevel, information asymmetry can be reduced by the formation of a system of officials' remuneration depending on the results in relevant sectors of the national economy, the delegation of responsibility for decision-making to the level of direct executors. Such measures may include:

- $\quad$ establishment of wage standards depending on the success of the economy;

- growth of economic compensation in various spheres;

- $\quad$ the dependence of wages on the amount of taxes paid by companies and citizens.

\section{Microlevel Approach}

Information produced by economic entities is an additional indicator of economic growth in the context of the development of information technologies and innovation. It seems necessary to consider in detail this correlation at the microlevel (the relationship between changes in the firm's economic indicators and produced information).

At the microlevel, there is a direct dependence of the target audience on the amount of information provided about the firm and products. With the growth of the target audience, the share of the consumer market is rising, so the company's economic growth is achieved. This model seems ideal, since the situation with information asymmetry is not considered (providing excessive, incomplete, unreliable or knowingly false information by companies, the presence of multiple competing firms that also disseminate information about their activities, products or services).

The market share of the firm with the appearance of information asymmetry decreases. There are reasons that trigger the emergence and growth of information asymmetry:

- A false idea of the complexity or simplicity of the purchase (for example, the information about some company and the quality of its goods became available to the individual, but this company gave inaccurate information about the possibilities of transporting its goods);

- false ideas about the properties of the goods form a negative attitude towards the firm (for example, the dissemination of unfair information by competitors).

At the microlevel in terms of reducing the information asymmetry e-government allows complying with the norms of state thinking and behavior, control over observance of ethical and moral norms by civil servants. Measures that can be taken include:

- development of basic values' list due to the behavior of a civil servant as a person representing the state;

- wide coverage of these ethical values in press, publications in printed and electronic editions in cases of ethical values' violation;

- deprivation of civil servant of any accumulated privileges in the case of neglect ethical values.

At the micro level in Azerbaijan, a problem affecting the sphere of relations between departmental bodies and individuals has always existed and continues to exist. We are talking about the professionalism of officials: the authorities received and continue to receive many reproaches in excessive bureaucracy, red tape, injustice, unfounded actions, rudeness and corruptness of their employees. In order to overcome the bureaucracy by electronic state mechanisms, it is possible carrying out activities to establish special simplified procedures: reduction time for procedural formalities, providing participants with the information they need, introduction information technologies, including the electronic declaration.

Thus, because of the formation of the world and interconnected local information and communication networks, there is a relative equalization of information asymmetry. This process leads to a decrease of administrative barriers in view of reduction of possibilities on extracting bureaucratic rent by virtue of electronic information about violations in the networks that cannot be hidden from the public. The level of independence in decision-making loses its significance due to the presence of a great number of information sources. The concentration of the functions on making the final decision in the top of a hierarchy begins to decrease its value, while an increase in the level of information accessibility makes the coordination of routine actions by "superiors" inexpedient and time-consuming.

\section{Conclusions}

The electronic management system provides handling the necessary information and performing legal transactions of any natural or legal person via Internet. With such a scheme of relationships, citizens can count on 
improving the efficiency of public administration and limiting corruption. Electronic governance can change the very nature of power, make it more transparent and controlled by the public, and ensure the real participation of citizens in different processes.

It should be noted that the placement of information in electronic form, on the one hand, helps to reduce its asymmetry between interaction participants in the process of information exchange, but on the other - opens the door for collusion and other forms of opportunistic behavior of dishonest participants.

The electronic state allows achievement the most positive results:

- modernization (use of modern technologies in accumulation, processing and distribution of information in the society);

- motivation (stimulation of labor in accordance with the market principle orientation to the result);

- humanization (the extension of social responsibility to the relationships between government and business).

Analysis of the asymmetric information influence on the bureaucratization of the Azerbaijan economy made it possible to propose the following measures to reduce it:

- $\quad$ at the macrolevel - the formation of a model of a subsidiary state that interacts with civil society and is characterized by the openness and accessibility of information on public services through the e-government system, homogeneity of the provided information;

- $\quad$ at the mesolevel - the system formation of officials' remuneration depending on the results achieved in the relevant sectors of the national economy, delegation of responsibility for decision-making to the direct executors;

- at the microlevel - the implementation of the governmental thinking and adequate norms of bureaucratic behavior, control over the ethical and moral standards by civil servants.

\section{REFERENCES}

[1] Anti-Corruption Reforms in Eastern Europe and Central Asia: Progress and Challenges: 2013-2015, OECD 2016

[2] N. G. Mankiw. The Macroeconomist as Scientist and Engineer, Journal of Economic Perspectives, Vol. 20, No. 4, 29-46, 2006.

[3] E. Domar. The Problem of Capital Formation, American Economic Review, No. 38, 777-794, 1948.

[4] A. Nelson. Theory of the Low Level Equilibrium Trap, American Economic Review, No. 46, 894-908, 1956.

[5] H. Leibenstein. Economic Backwardness and Economic Growth. New York: John Wiley and Sons, 1957.
[6] W. Rostow. The Take-Off into Self-Sustained Growth, The Economic Journal, Vol. 66, No.261, 25-48, 1960

[7] A. Hirschman, The Strategy of Economic Development, New Haven: Yale University Press, 1958.

[8] J. E. Stiglitz, Risk and Global Economic Architecture: Why Full Financial Integration May Be Undesirable, NBER Working Paper, No. 15718, February 2010.

[9] J.-M. Siroën. L’international n'est pas le global: Pour un usage raisonne du consept de globalization, Revue d'économie politique, No. 6, 681-698, 2004.

[10] A. Quliyeva, U. Rzayeva, Analysis of the de-dollarization problem in developing countries on the example of Azerbaijan in the conditions of geopolitical asymmetry, Technology Audit and Production Reserves, Vol. 6/5, No. 38, 57-63, 2017.

[11] A.M. Kacowicz. Globalization, Poverty, and the North-South Divide, International Studies Review, Vol. 9, No. 4, 565-580, 2007.

[12] L. Quest, Political Order and Political Decay: From the Industrial Revolution to the Globalization of Democracy by Francis Fukuyama, International Social Science Review, Vol. 91, Iss. 1, Article 15, 2015, Available at: http://digitalcommons.northgeorgia.edu/issr/vol91/iss1/15 C.

[13] Coglianese, Optimizing Government for an Optimizing Economy, University of Pennsylvania Law School, Faculty Scholarship. Paper 1646, 2016

[14] A. Molitorisova, Horizontal Cooperation between National Courts in the EU. An Empirical Study, Uppsala Faculty of Law Working Paper 2013, A. Benz, Two types of multilevel governance: Intergovernmental relations in German and EU regional policy, Regional \& Federal Studies, Vol. 10(3), 21-44, 2000

[15] Ch. Polidano, D. Hulme, Public Management Reform in Developing Countries: Issues and Outcomes, Public Management, Vol. 1(1), 121-132, 1999.

[16] A. Quliyeva, U. Rzayeva, Overcoming information asymmetry by the means of information and communication technologies as a condition of competitive advantages, 2-nd Congress International and Administrative Perspectives: Sustainable Global Copetition, Isparta, Turkey, October 05-07, 2017

[17] R. Coase. The Nature of the Firm, Economica, New Series, Vol. 4, No.16, 386-405, 1937.

[18] Y. Lebedeva, Contradictions of realizing the interests of officials and economic actors in modern Russia, Journal of International Scientific Publications: Economy \& Business, Vol. 4, No. 2, 106-113, 2010.

[19] E. Gushchina, Theoretic and Methodological Approaches to the Study of the Mechanism of Overcoming Negative Effects from Information Asymmetry as a Tool for Increasing Stability of Social And Economic Development in Russian Territories, Sustainable Development of Science and Education, No. 7, 23-29, 2017.

[20] E.M. Dianova. Electronic Government as a Mechanism for Influencing Transaction Costs in the Public Sector, Information Society, No. 4, 34-41, 2012. 
[21] R.F. Azizov, Electronic State - Theoretical Aspect \& Practical Experience of Azerbaijan, Internet conference "Law and Internet”, 1.10.06 - 31.10.06

[22] Development Concept "Azerbaijan 2020: Looking into the future". Online Available: http://www.president.az/files/future_az.pdf.

[23] The Strategic Road Map for development of communication and information technologies in the Republic of Azerbaijan. Online Available: http://mida.gov.az/documents/Telekommunikasiya_inform asiya_texnologiyalarının_inkişafına_dair_strateji_yol_xerit esi.p $\overline{d f}$

[24] L.V. Kolyazina. The formation of e-government as a direction of development of state regulation in conditions of new technological structures, Bulletin of the Saratov State Social and Economic University, №5, 2011, Online Available:

http://cyberleninka.ru/article/n/formirovanie-elektronnogopravitelstva-kak-napravlenie-razvitiya-gosudarstvennogo-r egulirovaniya-v-usloviyah-novyh-tehnologicheskih

[25] K. Arrow, G. Debreu, Existence of Equilibrium for a Competitive Economy, Econometrics, The Econometric Society. 22 (3), 265-90, 1954, DOI: 10.2307/1907353.

[26] Decent work indicators: guidelines for producers and users of statistical and legal framework indicators: ILO manual: second version / International Labor Office. - Geneva: ILO, 2013 